This document is the accepted manuscript version of the following article:

Kim, B. J., Fabbri, E., Abbott, D. F., Cheng, X., Clark, A. H., Nachtegaa1, M., ... Schmidt, T. J. (2019). Functional role of Fe-doping in Co-based perovskite oxide catalysts for oxygen evolution reaction. Journal of the American Chemical Society, 141(13), 5231-5240. https://doi.org/10.1021/jacs.8b12101

\title{
Functional Role of Fe-doping in Co-based Perovskite Oxide Catalysts for Oxygen Evolution Reaction
}

\author{
Bae-Jung Kim, ${ }^{\S, *}$ Emiliana Fabbri, ${ }^{\S, *}$ Daniel F. Abbott, ${ }^{\S}$ Xi Cheng, ${ }^{\S}$ Adam H. Clark, ${ }^{\S}$ Maarten \\ Nachtegaal, ${ }^{\S}$ Mario Borlaf, ${ }^{\dagger}$ Ivano E. Castelli, ${ }^{\ddagger}$ Thomas Graule, ${ }^{\dagger}$ and Thomas J. Schmidt ${ }^{\S, \perp}$ \\ § Energy \& Environment Division, Paul Scherrer Institut, Forschungstrasse 111, 5232 Villigen PSI, Switzerland \\ † Laboratory for High Performance Ceramics, Empa, Swiss Federal Laboratories for Materials Testing and Research, \\ 8600 Dübendorf, Switzerland \\ ‡ Department of Energy Conversion and Storage, Fysikvej 309, Technical University of Denmark, DK-28oo, Kgs. \\ Lyngby, Denmark \\ ${ }^{\perp}$ Laboratory of Physical Chemistry, ETH Zürich, CH-8093 Zürich, Switzerland
}

\section{KEYWORDS}

Fe-doping, operando X-ray absorption spectroscopy, oxygen evolution reaction, perovskite catalysts, water splitting.

\begin{abstract}
Perovskite oxides have been at the forefront among catalysts for the oxygen evolution reaction (OER) in alkaline media offering a higher degree of freedom in cation arrangement. Several of highly OER active Co-based perovskites have been known to show extraordinary activities and stabilities when the B-site is partially occupied by Fe. At the current stage, the role of $\mathrm{Fe}$ in enhancing the OER activity and stability is still unclear. In order to elucidate the roles of $\mathrm{Co}$ and $\mathrm{Fe}$ in the OER mechanism of cubic perovskites, two prospective perovskite oxides - $\mathrm{La}_{0.2} \mathrm{Sr}_{0.8} \mathrm{Co}_{1-x} \mathrm{Fe}_{\mathrm{x}} \mathrm{O}_{3-\delta}$ and $\mathrm{Ba}_{0.5} \mathrm{Sr}_{0.5} \mathrm{Co}_{1-\mathrm{x}} \mathrm{Fe}_{\mathrm{x}} \mathrm{O}_{3-}$ $\delta$ with $\mathrm{x}=\mathrm{o}$ and 0.2 - were prepared by flame spray synthesis as nanoparticles. This study highlights the importance of Fe in order to achieve high OER activity and stability by drawing relations between their physicochemical and electrochemical properties. Ex situ and operando X-ray absorption spectroscopy (XAS) was used to study the local electronic and geometric structure under oxygen evolving conditions. In parallel, density function theory computational studies were conducted to provide theoretical insights into our findings. Our findings show that the incorporation of Fe into Co-based perovskite oxides alters intrinsic properties rendering efficient OER activity and prolonged stability.
\end{abstract}

\section{INTRODUCTION}

The oxygen evolution reaction (OER) is the key half-cell reaction in water splitting process required for electrochemical energy conversion and storage systems such as hydrogen fuel cells and water electrolyzers. Perovskite oxides $\left(\mathrm{ABO}_{3}\right)$ have been recently under the spotlight as being efficient electrocatalysts for oxygen evolution reaction in alkaline electrolytes. Among them, $\mathrm{Ba}_{0.5} \mathrm{Sr}_{0.5} \mathrm{Co}_{0.8} \mathrm{Fe}_{0.2} \mathrm{O}_{3^{-}}$ ${ }_{\delta}$ (BSCF) has demonstrated a high activity. ${ }^{1-5}$ An extensive studies have been carried out to understand its exceptional performance in alkaline media..$^{-13}$ As first reported by Suntivich et. al., the authors have elucidated its outstanding activity based on molecular orbital theory.3, ${ }^{14}$ Several descriptors have been postulated for BSCF with other Cobased perovskite catalysts based on physicochemical properties to unravel the origin of the OER activity. ${ }^{15-18}$ Our recent study has taken advantages of operando X-ray absorption spectroscopy (XAS) for a detailed investigation of the electronic and geometric structure changes during the OER process. ${ }^{1}$ Diverging from more conventionally conceded activity descriptors, ${ }^{3,14}$ our study suggested the formation of a dynamic self-assembled surface oxy(hydroxide) layer of B-site cations (i.e. Co/Fe for BSCF) as the key feature to attain a high OER activity. ${ }^{1}$ The self-assembled $\mathrm{Co} / \mathrm{Fe}$ oxy(hydroxide) is the result of the lattice oxygen evolution reaction (LOER), which seems to be facilitated by structural flexibility and high oxygen vacancy content as exhibited by BSCF produced via flame spray synthesis.", 19 Likewise, substantial studies have emphasized the importance of the formation of oxy(hydroxide) within the OER reaction mechanism. ${ }^{20-28}$ With regards to the formation of oxy(hydroxide) layers, interestingly, many transition metal oxy(hydroxide) were found to be more active towards OER when a relatively small amount of $\mathrm{Fe}$ is present in the structure. ${ }^{29-37}$

Considering high temperature applications (such as solid oxide fuel cells) of perovskite oxides as a cathode catalyst, the addition of Fe into the perovskite structure provides lowering of thermal expansion coefficient, which is critical in high temperature applications. $3^{8-39}$ Yet, even for a low temperature application $\left(<100{ }^{\circ} \mathrm{C}\right)$, such as water splitting reaction, the presence of Fe in the B-site of perovskite oxides has shown favorable effects on its activity and

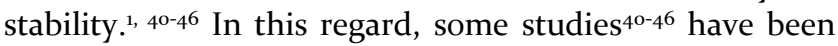
carried out to understand the synergetic effect of Fe-doping in perovskite oxides; still, the explicit role of Fe is yet to be unraveled. Therefore at this stage, gaining thorough understandings of the role of Fe-doping in perovskite catalyst is vital for the future development of OER catalysts.

In this present work, we investigate the functional role of Fe in enhancing the OER activities and stabilities of two active Co-based perovskite catalysts, BSCF and $\mathrm{La}_{0.2} \mathrm{Sr}_{0.8} \mathrm{Co}_{0.8} \mathrm{Fe}_{0.2} \mathrm{O}_{3-\delta}$ (LSCF), by comparing their performance to $\mathrm{Ba}_{0.5} \mathrm{Sr}_{0.5} \mathrm{CoO}_{3-\delta}$ (BSC) and $\mathrm{La}_{0.2} \mathrm{Sr}_{0.8} \mathrm{CoO}_{3-\delta}$ (LSC), 
respectively. All materials under study are prepared by flame spray synthesis in order to obtain nanoparticles. This not only allows enhances OER activities but also enables us to keenly study changes in their physio-chemical properties while electrochemical reactions occur at an interfacial level. From our findings, the self-assembled oxy(hydroxide) layer formation on Co-based perovskites is further verified and confirmed in relation to the presence of Fe at the B-site of the Co-based catalysts. In parallel, we related to density functional theory based calculations to provide theoretical perspective in their electronic states and performances from thermodynamic perspective. Integrating the experimental and theoretical findings, the functional role of Fe in Co-based perovskite catalysts for OER is underlined.

\section{EXPERIMENTAL METHODS}

Material Synthesis. BSC, LSC, BSCF, and LSCF have been synthesized by flame spray synthesis. ${ }^{47}$ Barium carbonate $\left(\mathrm{BaCO}_{3}, \geq 99 \%\right.$, Sigma-Aldrich), lanthanum oxide $\left(\mathrm{La}_{2} \mathrm{O}_{3},>99.99 \%\right.$, Auer Remi) strontium nitrate $\left(\mathrm{Sr}\left(\mathrm{NO}_{3}\right)_{2}\right.$, $\geq 98 \%$, Sigma-Aldrich, Germany), cobalt nitrate hexahydrate $\left(\mathrm{Co}\left(\mathrm{NO}_{3}\right)_{2} \cdot 6 \mathrm{H}_{2} \mathrm{O}, 99.9 \%\right.$, Auer Remy, Germany) and iron nitrate nonahydrate $\left(\mathrm{Fe}\left(\mathrm{NO}_{3}\right)_{3} \cdot{ }_{9} \mathrm{H}_{2} \mathrm{O}, \geq 98 \%\right.$, SigmaAldrich) were used as precursors. BSC and BSCF precursor solutions were prepared by dissolving barium carbonate in a mixture of water and nitric acid $\left(\mathrm{HNO}_{3}, 70 \%\right.$, Sigma-Aldrich) and then, when no more $\mathrm{CO}_{2}$ bubbles were observed, the rest of the corresponding metal precursors. After that, acetic acid (HAc, $\geq 99.0 \%$, Sigma-Aldrich, Germany) was added to obtain a solvent composition of $\mathrm{HAc}: \mathrm{HNO}_{3}: \mathrm{H}_{2} \mathrm{O}$ = 25:1:74 in volume. LSC and LSCF were prepared by dissolving the lanthanum oxide in concentrated nitric acid. The obtained product and the rest of the precursors were added into a mixture of N,N-dimethylformamide (DMF, $\geq 99.8 \%$, Switzerland), acetic acid and water, obtaining a final volume ratio of 50:20:30, respectively. In all cases, the total metal concentration in the precursor solution was 0.2 M.

The precursor solutions were pumped into the flame by using a three piston pump (C-6o1, Büchi, Switzerland) with a flow controller (C-610, Büchi, Switzerland), using in all cases a constant flow free of pulsations of $20 \mathrm{~mL} \mathrm{~min}^{-1}$. The nozzle is formed by a commercial flame cutter (Type 15020o, Pangas, Switzerland) modified with a centered capillary $(\varnothing$ inner $=1.05 \mathrm{~mm}, \varnothing$ outer $=1.6 \mathrm{~mm})$, allowing an axial injection of the liquid precursors. The capillary is surrounded by a circular gap $(\varnothing=3 \mathrm{~mm})$ through which the dispersion gas is provided. Pure oxygen (99.95\%, Carbagas, Switzerland) was used as dispersion gas with a flow rate of $35 \mathrm{~L} \mathrm{~min}^{-1}$ ( $45 \mathrm{~L} \mathrm{~min}^{-1}$ for LSC and LSCF). The combustion gas was formed by acetylene (99.6\%, Carbagas, Switzerland), with a flow rate of $13 \mathrm{~L} \mathrm{~min}^{-1}$, and pure oxygen (17 L $\mathrm{min}^{-1}$ for BSC and BSCF, and $30 \mathrm{~L} \mathrm{~min}^{-1}$ for LSC and LSCF). The rates of the gases were measured by a mass flow controller (Bronkhorst, Netherlands). Finally, the powders were collected in a baghouse filter (Friedli AG, Switzerland) but representative powder samples were simultaneously collected on four ashless paper filters (Whatman, SigmaAldrich) using a by-pass inlet with two vacuum pumps.

Material Characterizations. Phase characterization of prepared materials was performed using powder X-ray diffraction (XRD, Bruker D8 system in Bragg-Brentano geometry, $\mathrm{Cu} K \alpha$ radiation $(\lambda=0.15418 \mathrm{~nm})$ ). The diffractometer is equipped with a rotating $\mathrm{Cu}$ anode. Specific surface area was calculated by Brunauer-Emmett-Teller (BET) analysis of $\mathrm{N}_{2}$ adsorption / desorption isotherms (AUROSORB-1, Quantachrome). Transmission electron microscopy (TEM) (TECNAI F3o operated at $300 \mathrm{kV}$ for transmission imaging) were used to study the surface morphology of the prepared materials.

For ex situ and operando X-ray absorption spectroscopy (XAS) measurements, the ink was prepared by dispersing catalyst powders in a mixture of isopropanol and Milli-Q water in the equal ratio sonicated for $30 \mathrm{~min}$. The ink was then spray coated on Kapton film. XAS spectra at the Co Kedge and Fe K-edge were recorded at the SuperXAS beamline of the Swiss Light Source (PSI, Villigen, Switzerland). The incident photon beam provided by a $2.9 \mathrm{~T}$ superbend magnet source was collimated by a Si-coated mirror at 2.85 $\mathrm{mRad}$ (which also served to reject higher harmonics) and subsequently monochromatized by a Si (111) channel-cut monochromator. Rh-coated toroidal mirror at $2.5 \mathrm{mRad}$ was used to focus the X-ray beam to a spot size of $1 \mathrm{~mm}$ by $0.2 \mathrm{~mm}$ maximal on the sample position. The SuperXAS beamline ${ }^{8}$ allowed for the rapid collection of 120 spectra during a measurement time of 6o sec (QEXAFS mode), which were then averaged. The spectra of samples were collected in transmission mode using $\mathrm{N}_{2}$ filled ionization chambers, where a Co foil was located between the second and third ionization chamber served to calibrate and align all spectra. Extended X-ray absorption fine structure (EXAFS) spectra were analyzed using the Demeter software package, ${ }^{49}$ which included background subtraction, energy calibration (based on the simultaneously measured Co or Fe reference foil) and edge step normalization. The resulting spectra were converted to the photoelectron wave vector $k$ (in units $\AA^{-1}$ ) by assigning the photoelectron energy origin, $E_{\mathrm{o}}$, corresponding to $k=0$, to the first inflection point of the absorption edge. The resulting $\chi(k)$ functions were weighted with $k^{3}$ to compensate for the dampening of the EXAFS amplitude with increasing $k$. These $\chi(k)$ functions were Fourier transformed over $3-12 \AA^{-1}$ and subsequently fitted. The theoretical models used for the EXAFS fittings of BSC and BSCF were generated from $\mathrm{CoOOH}^{50}$ for the $\mathrm{Co}-\mathrm{O}$ coordination shell and the first $\mathrm{Co}^{-}$ Co shell at $\sim 2.5-2.7 \AA$, and from $\mathrm{Co}(\mathrm{OH})_{2}{ }^{51}$ for the second Co-Co shell at $\sim 2.7-3.0 \AA$; for the EXAFS fittings of LSC and LSCF, the theoretical models were generated from La$\mathrm{CoO}_{3}{ }^{52}$ for the $\mathrm{Co}-\mathrm{O}$ shell, and from $\mathrm{CoOOH}^{50}$ for the CoCo shell structure using the FEFF6.2 library. Refer to Supplementary Information $\mathrm{S}_{7}$ for detailed description of EXAFS fittings.

Electrochemical Characterization. The electrochemical activities of the prepared catalysts were evaluated in a standard three-electrode electrochemical cell using the thin-film rotating disk electrode (RDE) methodology. The 
setup for oxygen evolution reaction (OER) and cyclic voltammetry (CV) consists of a potentiostat (Biologic VMP30o) and a rotation speed controlled motor (Pine Instrument Co., AFMSRCE). All the electrochemical measurements were performed at room temperature using Reversible hydrogen electrode (RHE) as the reference electrode in o.1 M potassium hydroxide $(\mathrm{KOH})$. A piece of platinum or gold mesh was used as the counter electrode. A homemade Teflon cell was used to contain the electrolyte with the working electrode immersed under the potential control. A porous thin film of materials was prepared by drop-casting a catalyst ink ( $0.02 \mathrm{mg}$ of catalyst) on a polished glassy carbon electrode $\left(5 \mathrm{~mm}\right.$ OD / $0.196 \mathrm{~cm}^{2}$ ), resulting in 0.102 mgoxide $\mathrm{cm}^{-2} .{ }^{53}$ The catalyst ink was prepared from a catalyst suspension made from sonicating (Bandelin, RM $16 \mathrm{UH}$, $300 \mathrm{Weff}, 40 \mathrm{kHz}$ ) $10 \mathrm{mg}$ of catalyst in a solution mixture of $4 \mathrm{~mL}$ isopropyl alcohol and $1 \mathrm{~mL}$ of Milli-Q water (ELGA, PURELAB Chorus), and $20 \mu \mathrm{L}$ of ion-exchanged Nafion (Sigma-Aldrich, 5 wt. \%). 54 The o.1 M KOH electrolyte was prepared by dissolving $\mathrm{KOH}$ pellets (Sigma-Aldrich, $99.99 \%)$ in Milli-Q water. Initially, 25 reverse potentiostatic sweeps of CV were performed in the synthetic airsaturated electrolyte from 1.o to $1.7 \mathrm{~V}_{\mathrm{RHE}}$ at a scan rate of 10 $\mathrm{mV} \mathrm{s}^{-1}$. Afterwards, series of chronoamperometry measurements were carried out holding each potential step for 30 seconds to obtain steady-state currents in the potential range from 1.2 to $1.7 \mathrm{~V}_{\mathrm{RHE}}$ while rotating the working electrode at $900 \mathrm{rpm}$. Tafel plots were constructed from the resulting polarization curves for all materials under study for an effective comparison of OER activities. The potential stability of catalyst materials was conducted using the same setup; alternating electrode potential between 1.0 $\mathrm{V}_{\mathrm{RHE}}$ and 1.6 $\mathrm{V}_{\mathrm{RHE}}$ for 500 times holding for 10 seconds each to reach steady-state at each potential. The stability plot is plotted by recording current densities at $1.6 \mathrm{~V}_{\text {RHE }}$. Five cycles of $\mathrm{CV}$ and electrochemical impedance spectroscopy (EIS) was carried out after every 100 cycles. All measured currents were normalized by the mass of catalyst loading, and potentials were corrected for the ohmic drop obtained from EIS.

Operando Flow Cell Test. The homemade operando XAS electrochemical flow cell used in this study was extensively described previously. 55 The electrode materials were spray coated at the center of Kapton films. Black pearl

In the second set of calculations, the effects of the Fe content on the oxidation states of Co were determined.To decouple different effects, namely the change in the composition and in the crystal structure (lattice and distortions) due to different Fe content, only the perfect cubic structure was considered while composition was varied between $x=$ 1-8 for $\mathrm{Ba}_{0.5} \mathrm{Sr}_{0.5} \mathrm{Co}_{x / 8} \mathrm{Fe}_{1-(x / 8)} \mathrm{O}_{3}, \mathrm{La}_{0.25} \mathrm{Sr}_{0.75} \mathrm{Co}_{x / 8} \mathrm{Fe}_{1-(x / 8)} \mathrm{O}_{3}$, and $\mathrm{La}_{0.125} \mathrm{Sr}_{0.875} \mathrm{Co}_{x / 8} \mathrm{Fe}_{1-(x / 8)} \mathrm{O}_{3}$ (two different ratios of $\mathrm{La}$ and $\mathrm{Sr}$ were calculated to better estimate for $\mathrm{La}: \mathrm{Sr}=1: 4)$. These calculations have been performed using the GPAW code. ${ }^{67^{-}}$ 68 The electronic Z-charges on each atoms are then calculated using the Bader partition scheme. ${ }^{69}$ Note that the charges calculated using DFT are small compared with what is measured in experiments, which the detailed explanation can be found here. ${ }^{70}$
(Cabot Corp.) was used as the counter electrode material. A silver chloride electrode $\left(\mathrm{Ag}^{+} / \mathrm{AgCl}\right)$ (Hugo Sachs Elektronik) was used as the reference electrode. During electrochemical testing, the electrolyte was drawn into the cell and collected in a syringe at the flow rate of $0.1 \mathrm{~mL} \mathrm{~min}^{-1}$. The chronoamperometry measurement was carried out holding for $120 \mathrm{sec}$ at each increasing potential step from 1.2 $\mathrm{V}_{\mathrm{RHE}}$ to $1.54 \mathrm{~V}_{\mathrm{RHE}}$, and again during the reverse sequence back to 1.2 $\mathrm{V}_{\mathrm{RHE}}$. At each potential step, both transmission XAS spectra at the Co and Fe K-edges were collected simultaneously for 60 seconds. Subsequently, the stability test was carried out by alternating potentials from 1.0 $\mathrm{V}_{\mathrm{RHE}}$ to 1.6 $\mathrm{V}_{\mathrm{RHE}}$ for 200 times holding for 10 seconds each to reach steady-state at each potential. After every 100 cycles the potential is held at $\mathbf{1 . 2} \mathrm{V}_{\mathrm{RHE}}$ for recording of XAS spectra. In addition, electrochemical impedance spectroscopy (EIS) was measured before and after the stability test. The energy position of the Co and Fe K-edge are determined at the half edge-step intensity.

Density Functional Theory Calculations - Pourbaix Diagram and Cation Charge. Density Functional Theory (DFT) calculations are used to help understand the experimental data. In the first set of calculations, the stability of the perovskites in an aqueous environment was investigated by means of Pourbaix diagrams. This method has been previously used to investigate the stability of $\mathrm{Ru}$ based perovskite oxides in water as a descriptor for the stability in water to identify novel light harvesting materials. ${ }^{56}$ Pourbaix diagrams were constructed to show the phase diagram of solid and dissolved species as a function of $\mathrm{pH}$ and external potential based on the total energies for the solid bulk of perovskites and the other solids competing phases as described in the Materials Project database. 57 The ion concentrations of $10^{-6} \mathrm{M}$ were used. Experiments provide the dissolution energies for the dissolved species. ${ }^{58-59}$ This method is implemented in the Atomic Simulation Environment (ASE) package, ${ }^{60}$ and more details about the methodology can be found in the literature. ${ }^{61-62}$ All the bulk structures have been fully relaxed using the Quantum ESPRESSO code, ${ }^{63}$ PBEsol as exchange-correlation functional $^{64}$ with a Hubbard $+\mathrm{U}$ correction of $2 \mathrm{eV}$ applied to the p-orbitals of $\mathrm{O}$, and d- orbitals of the transition metals and the pseu-dopotentials from the Standard Solid State Pseudopotential library (SSSP accuracy). ${ }^{65-66}$

\section{RESULTS AND DISCUSSION}

All of perovskite catalysts - BSC, LSC, BSCF and LSCF are prepared via flame spray synthesis to obtain nano-sized catalyst particles. We have previously confirmed the electrocatalytic advantages of preparing perovskite oxides by flame spray synthesis., ${ }^{11} \mathrm{X}$-ray diffraction analysis (XRD) revealed that all of the prepared perovskites are in cubic phase with the Fe-doped perovskites showing smaller lattice parameters than their control perovskite oxides (i.e. BSC and LSC) (refer to Figure S1). Considering that the undoped and the Fe-doped perovskite oxides are both cubic, the observed differences in their activity and stability which will be further discussed later in this study would 

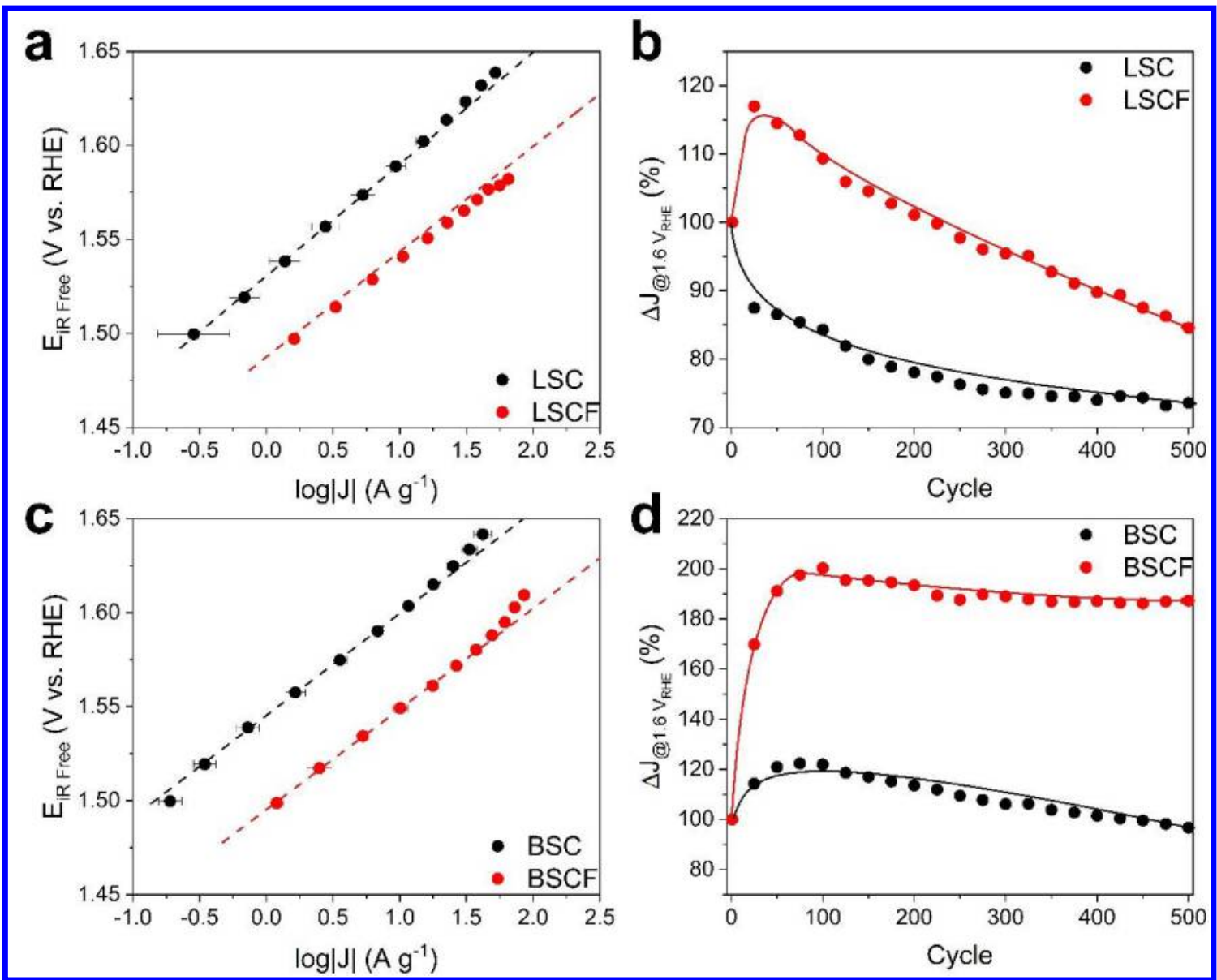

Figure 1. Tafel plots comparing OER activities and mass normalized current densities recorded over 50o cycles at 1.6 $\mathrm{V}_{\mathrm{RHE}}$; a - b) LSC and LSCF, and c - d) BSC and BSCF, respectively insignificantly reflect upon their structural properties. Refer to Supplementary Information Si for further physical characterizations of the prepared catalysts.

The effect of Fe-doping in perovskite oxides is clearly manifested in their electrochemical performances. Figure 1 shows the electrochemical benefits of having Fe present in the Co-based perovskite catalysts in terms of activity and stability. LSCF demonstrates $\sim 6$ times higher current density in the OER regime compared to LSC (Figure 1a). Additionally, LSCF reveals an initial increase of current density during the stability test, while LSC shows a constant decrease in current density (Figure $\mathrm{ib}$ ). The presence of $\mathrm{Fe}$ leads to similar but more distinctive differences between BSC and BSCF. Figure 1c shows a similar Tafel slope for BSC and BSCF (Table $\mathrm{S} 1$ ), yet, BSCF demonstrates $\sim 10$ times higher current density than BSC at $1.55 \mathrm{~V}_{\text {RHE}}$. This might suggest that the Fe-doped perovskite catalysts would undergo similar OER pathways as the undoped perovskite catalysts. Then, the drastic enhancement in activity without significant change in Tafel slope would lead to consider that Fe offers synergetic effect in other parameters. For instance, Burke and coworkers reported that that the incorporated Fe would allow easier oxy(hydroxide) formation by increasing the electrochemical accessibility, which may be result of increased disorder or number of defects. ${ }^{29}, 7^{2}$ In terms of stability, BSCF shows an amplified current density at the end of 500 cycles, whereas BSC shows a decreasing

trend of current density with cycling (Figure id). Overall, the benefit of the presence of $\mathrm{Fe}$ is highlighted in both LSCF and BSCF demonstrating superiority in both activity and stability compared to the same perovskites without Fe.

In order to elucidate the functional role of $\mathrm{Fe}$ in the OER process, operando X-ray absorption spectroscopy (XAS) was used to monitor potential-induced changes in the local electronic and geometric structure of the prepared catalyst. 55 In parallel, DFT computational studies were conducted to provide theoretical insights into our findings.

In Figure 2a, the Co K-edge energy positions of normalized X-ray absorption near edge structure (XANES) spectra of as-prepared LSC and LSCF indicate that Co cations for both perovskites have valence states close to $3^{+}$, yet the Co $\mathrm{K}$-edge of the as-prepared LSCF is positioned at a lower energy position than that of LSC by $\sim 0.3 \mathrm{eV}$, suggesting a slightly lower Co valence state than in LSC. This is also projected from the DFT calculated Z-charge of the B-site cations of LSCF and LSC (refer to Figure S8a). Figure $2 b$ shows the comparison of the Fourier-transformed (FT) $\mathrm{k}^{3-}$ weighted Co K-edge extended X-ray absorption fine structure (EXAFS) spectra of the as-prepared LSC and LSCF, from which their local structure can be inferred. In this comparison, the FT-EXAFS spectrum of LSCF is almost indistinguishable from that of LSC. The two major peaks are observed for both LSC and LSCF at 1.91 Å and $2.84 \AA$. These peaks point to the presence of several neighboring atomic 

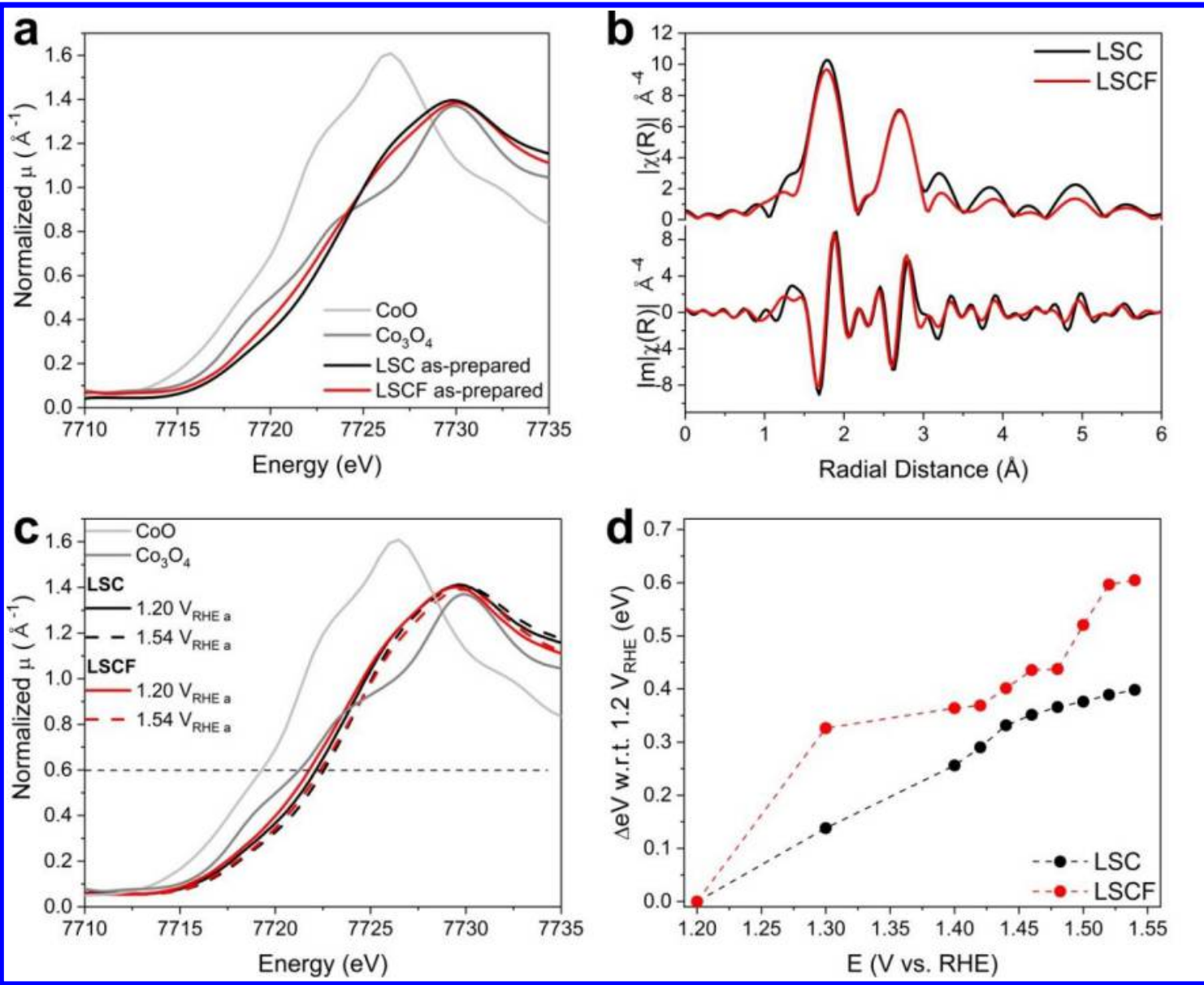

Figure 2. Comparison of as-prepared LSC and LSCF; a) Co K-edge XANES spectra, b) FT-EXAFS spectra; and their operando XAS study results c) comparison of Co K-edge XANES spectra recorded at 1.2 and $1.54 \mathrm{~V}_{\mathrm{RHE}}$; d) edge shift measured with respect to the edge position at 1.2 $\mathrm{V}_{\mathrm{RHE}}$ at each potential during operando flow cell test.

shells in the vicinity of Co. The first major peak is ascribable to the backscattering contributions from the nearest ligands and was best fitted with $\mathrm{O}$ atoms, and structural parameters derived from a multiple shell fit in $\mathrm{R}$ space are given Table $\mathrm{S}_{4}$.The second peak is the contribution from the $\mathrm{Co}-\mathrm{Co} / \mathrm{Fe}$ coordination. This $\mathrm{Co}-\mathrm{Co} / \mathrm{Fe}$ peak location can be found in a typical perovskite oxide with a high oxygen deficiency which generally renders edge-sharing polyhedra (refer to Supplementary Information $\mathrm{S}_{7}$ for the best fit parameters). . $3-74^{-74}$

Operando XANES measurements of LSC and LSCF show shifts of their Co K-edge positions during the anodic polarization (Figure $2 \mathrm{c}$ and $\mathrm{d}$ ). Comparing the XANES spectra of LSC and LSCF at $1.54 \mathrm{~V}_{\mathrm{RHE}}$ (Figure 2c), the Co K-edge energy positions are similar indicating that $\mathrm{Co}$ cations of both LSC and LSCF are oxidized to reach about the same valence state during the OER process. Nevertheless, as the Co Kedge position of as-prepared LSCF is at a slightly lower energy than that of LSC, LSCF manifests a greater average increase of Co oxidation state during OER. In our previous work, a positive correlation between the extent of increase in Co oxidation state (i.e. positive edge shift) at OER potentials and the activity was presented. ${ }^{1}$ Thus, the higher activity of LSCF could be elucidated by its larger Co K-edge shift compared to LSC (Figure 2d). Nevertheless, the edge position shifts even before the OER onset $\left(<1.4 \mathrm{~V}_{\mathrm{RHE}}\right)$ indicating that both LSC and LSCF go through physicochemical modifications attributed to (electro)chemical dissolution in addition to the LOER/OER processes, which is expected to start only above 1.4 $\mathrm{V}_{\text {RHE }}$. The dissolutions of LSC and LSCF are also anticipated by their density functional theory (DFT) calculated Pourbaix diagrams in which both LSC and LSCF show thermodynamic instability at potentials below the OER regime (refer to Figure Sga and b). The decreasing stability trends of both LSC and LSCF observed in the current densities recorded during the stability test (Figure $1 b$ ) also experimentally support their dissolution. Furthermore, it is noteworthy that in the FT-EXAFS spectra of LSC and LSCF, the Co-Co bond distance of the perovskite structure coincides with that of $\mathrm{Co}-\mathrm{O}(\mathrm{OH})(\sim 2.8$ $\AA$ ) $75-77$ (refer to Table $\mathrm{S}_{4} \mathrm{~b}$ for the best fit analysis) making it impossible to differentiate the $\mathrm{Co}-\mathrm{Co}$ contribution in LSCF from that in $\mathrm{Co}-\mathrm{O}(\mathrm{OH})$ (refer to Supplementary Information $\mathrm{S}_{5}$ for details). ${ }^{1}$ Henceforth, operando Co K-edge FT-EXAFS spectra of both LSC and LSCF do not show acknowledgeable changes in the $\mathrm{Co}-\mathrm{Co}$ coordination shell during the anodic polarization beyond the OER potential. Overall, for both LSC and LSCF, the increase in the Co oxidation state suggest the formation of an oxy(hydroxide) surface layer during OER. However, these observed 

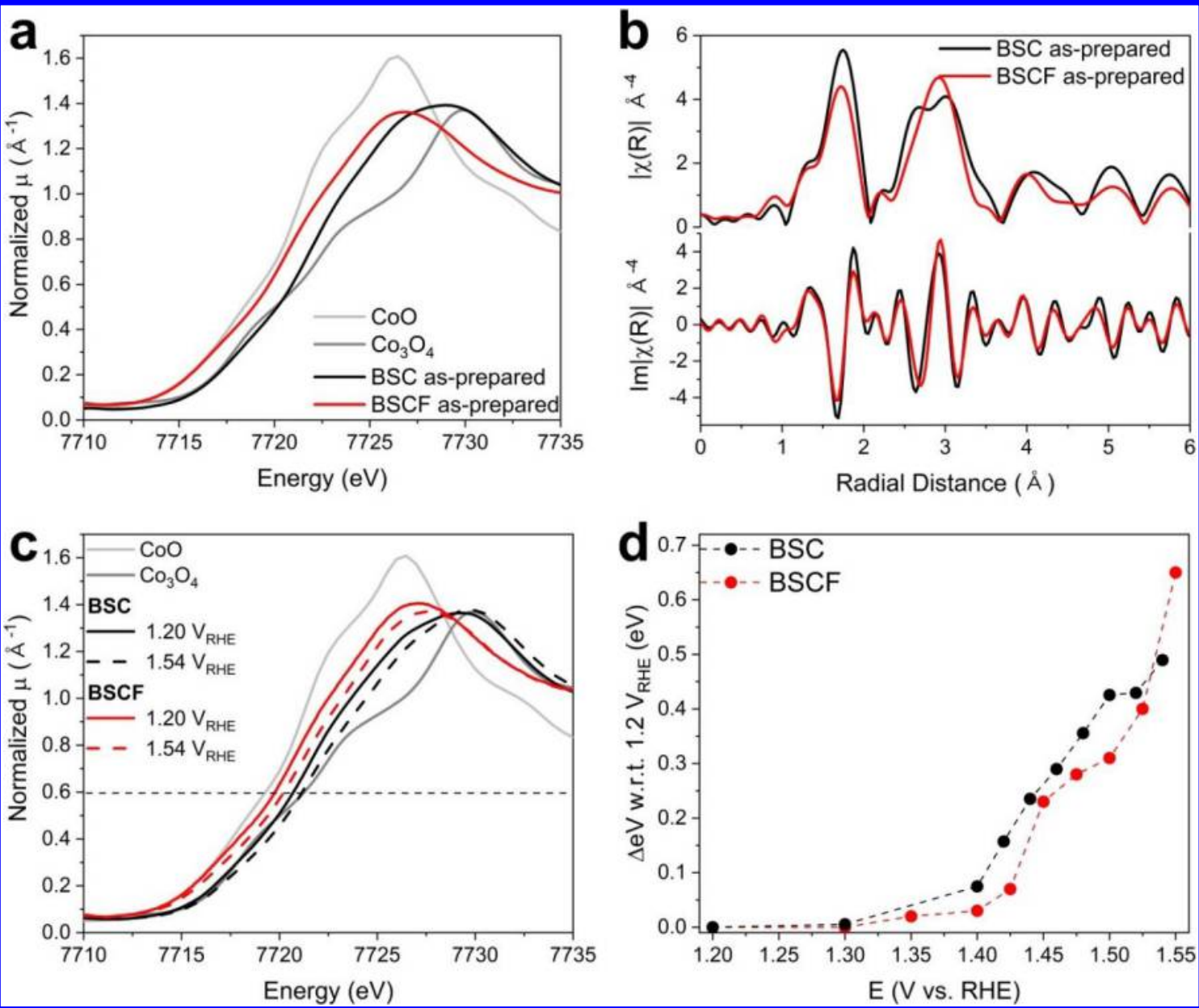

Figure 3. Comparison of as-prepared BSC and BSCF; a) Co K-edge XANES spectra, b) FT-EXAFS spectra; and their operando XAS study results c) comparison of Co K-edge XANES spectra recorded at 1.2 and $1.54 \mathrm{~V}_{\mathrm{RHE}}$; d) edge shift measured with respect to the edge position at $1.2 \mathrm{~V}_{\mathrm{RHE}}$ at each potential during operando flow cell tests.

changes could also be the result of the dissolution process which occurs even before the OER potential.

Furthermore, in situ XAS measurements were also carried out during the extended stability test to examine any further changes in the structure of LSC and LSCF. Both of these perovskites do not reveal any significant changes in the XAS spectra during the stability test (see Figure Sizad), which indicates no formation of new surface oxide species.

The as-prepared BSC and BSCF show similar but more distinctive changes in the Co K-edge energy position, where the as-prepared BSCF reveals a lower Co K-edge energy position than that of BSC by $\sim 1.2 \mathrm{eV}$ indicating a lower oxidation state closer to 2+ (Figure 3a). Again, the lower oxidation state of Co in BSCF compared to that of Co in BSC is supported by the DFT Z-charge calculations (refer to Figure S8b). This difference in the Co K-edge energy position of as-prepared BSC and BSCF is much greater than that between LSC and LSCF, which complies with the DFT Z-charge calculations.

Unlike in the case of LSC/LSCF, BSC and BSCF show clear differences in their FT-EXAFS spectra (Figure 3b). The best fit to the FT-EXAFS spectra of BSC and BSCF (Table $\mathrm{S}_{4 \mathrm{c}}$ and d, respectively) show a difference in $\mathrm{Co}-\mathrm{O}$ co- ordination number, where BSCF reveals a lower $\mathrm{Co}-\mathrm{O}$ coordination number $(5.1-5.5)$ than that of BSC $(5.4-6.2)$ concurring with the lower oxidation state of BSCF than BSC. Furthermore, the Co-Co coordination shell of as-prepared BSC displays two overlapping peaks at $\sim 2.8 \AA$ and $\sim 3.0$ Å manifesting two different $\mathrm{Co}$-Co bond distances attributable to $\mathrm{Co}-\mathrm{O}(\mathrm{OH})$ and $\mathrm{Co}-\mathrm{Co}$ in Co edge-sharing polyhedra of the perovskite, respectively (refer to Supplementary Information $S_{5}$ for details). In this regard, the asprepared BSCF shows a $\mathrm{Co}-\mathrm{Co}$ scatter with a bond distance $\sim 3.0$ A highlighting the predominant presence of the edgesharing polyhedra of the perovskite structure. To summarize, in the as-prepared BSC a considerable amount of amorphous side oxide phases would initially be present; whereas, for BSCF the presence of Fe seems to suppress the formation of these side oxide phases during the formation by promoting charge stability and a large amount of oxygen deficiency. ${ }^{1}$ Also, the presence of these plausible side oxide phases would explain a higher average Co oxidation state of as-prepared BSC than BSCF.

In order to study valence state changes during the OER process, XAS spectra of both BSC and BSCF were collected during anodic polarization. As displayed in Figure $3 \mathrm{c}$, XANES spectra of both BSC and BSCF indicate an increase 


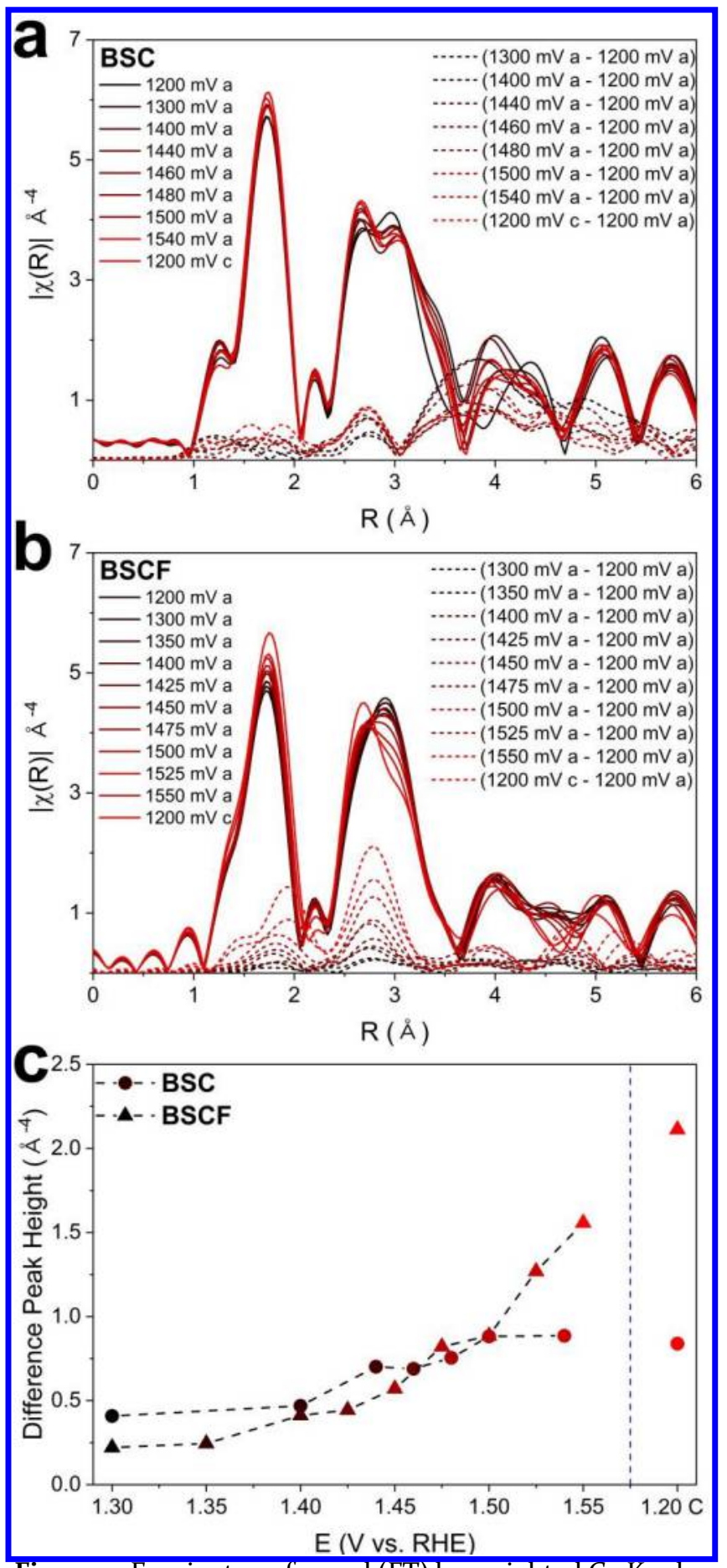

Figure 4. Fourier transformed (FT) k3-weighted Co K-edge EXAFS spectra of a) BSC and b) BSCF recorded during the operando XAS measurement (solid lines). FT difference spectra between individual spectrum and the spectrum rec-orded at 1.20 VRHE of the anodic polarization (dashed lines). The change in the amplitude of the Co-Co peak associated with self-constructed Co-oxy(hydroxide) in the difference spectrum at each potential of c) BSC and BSCF. The last point is the Co-Co peak height of the difference spectra at 1.2 VRHE of the cathodic polarization subsequent to the an-odic polarization. of the average Co oxidation state after polarization. During the anodic polarization, both BSC and BSCF show an exponential increase in the shift in the Co K-edge position after entering the OER potential regime ( $>1.4 \mathrm{~V}_{\mathrm{RHE}}$ ) (Figure 3d), which suggests that OER/LOER are the main contributors to the observed changes in the Co oxidation state. Furthermore, the extent of the shit of the Co K-edge position in BSCF $(\sim 0.7 \mathrm{eV})$ is larger than that of BSC $(\sim 0.5 \mathrm{eV})$. This difference in the extents of Co K-edge shift is correlated with their OER activity; BSCF demonstrates about 10 times higher activity than BSC (Figure 1c).

Furthermore, Figure $4 \mathrm{a}$ and $\mathrm{b}$ shows the operando FTEXAFS spectra of BSC and BSCF, respectively, recorded during the anodic polarization (displayed by solid lines); the imaginary parts are shown in Figure S18. A growth of the coordination peak at $2.8 \AA$ associated with the $\mathrm{Co}-\mathrm{Co}$ coordination shell of $\mathrm{Co}-\mathrm{O}(\mathrm{OH})$ is revealed during the OER process for both catalysts. While BSC shows a smaller growth in this contribution, BSCF shows a significant growth of this contribution, indicating the growth of a selfassembled Co oxy(hydroxide) layer, which is the result of LOER/OER processes ${ }^{19}$ and becoming the actual active surface. ${ }^{1}$ These data suggest that the presence of Fe offers charge stability to sustain $C o$ in a lower oxidation state and thus prevent the formation of side oxide phases. The side oxide phases may be at the BSC surface which then hinder the construction of self-assembled oxy(hydroxide) layer (i.e. inhibiting the growth of active surface) and thus lead to a lower OER activity (Figure 1c). In this essence, the maximal development of a self-assembled oxy(hydroxide) layer is required to attain a high OER activity. BSCF, with the presence of $\mathrm{Fe}$, seems to offer more appropriate conditions for the self-construction of the oxy(hydroxide) layer which might be the result of: (i) the near-absence of side oxide phases on its surface and (ii) the reduced Co oxidation state, ${ }^{29}$ which then leads to accommodate a larger amount of oxygen vacancies activating LOER and thereby promotes the formation of a self-assembled $\mathrm{Co}-\mathrm{O}(\mathrm{OH})$ layer. ${ }^{19}$, ${ }^{78-81}$ In addition, the thermodynamic meta-stability of BSCF (see Pourbaix diagram, Figure Sgd) appears to be another contributing property since it is anticipated to exhibit the ability to preserve its perovskite structure while cation species are partially dissolved to be reconstructed as metaloxy(hydroxide). In contrast, BSC would go through a typical dissolution of cations as anticipated by its DFT calculated Pourbaix diagram even when no potential is applied (see Figure S9c). Eventually, its perovskite structure would no longer be able to act as a suitable substrate for the growth of a surface oxy(hydroxide) layer. The Pourbaix diagram depicts its thermodynamic instability even at the open circuit potential highlighting its cation dissolution and clarifies its decreasing stability trend (as seen in Figure 1d). Meanwhile, in the presence of Fe, BSCF shows a wider window of meta-stability at $\mathrm{pH} 13$ in the working potential window, and thereby is able to maintain its perovskite structure for the dynamic growth of active oxy(hydroxide) layer.

Given that self-assembled $\mathrm{Co}-\mathrm{O}(\mathrm{OH})$ is the key feature for an efficient OER, therefore, it is essential to precisely 
monitor changes of the peak of FT-EXAFS spectra associated with the Co-Co coordination shell of $\mathrm{Co}-\mathrm{O}(\mathrm{OH})$. As discussed, Co K-edge FT-EXAFS spectra of both BSC and BSCF reveal two close radial distances which are both assigned to the $\mathrm{Co}-\mathrm{Co} / \mathrm{Fe}$ coordination shells of $\mathrm{Co}-\mathrm{O}(\mathrm{OH})$ $(\sim 2.8 \AA)$ and that of the edge-sharing Co polyhedron ( 3.0 $\AA$ A). Thus, these overlapping contributions compromise the precise determination of geometric structural changes. For this reason, difference spectra were determined by taking the difference in $\mu(E)$ of each spectrum recorded during the operando measurement with respect to the $\mu(E)$ spectrum taken at 1.2 $\mathrm{V}_{\mathrm{RHE}}$ were calculated. The resulting difference spectra were converted into k-space and Fouriertransformed over $3-12 \AA^{-1}$ (displayed by dashed lines in Figure $4 \mathrm{a}$ and $\mathrm{b}$ ).

As the first peak of FT-EXAFS spectrum is associated with the $\mathrm{Co}-\mathrm{O}$ coordination shell, Figure $4 \mathrm{a}$ and $\mathrm{b}$ shows an increase of the first peak intensity of difference spectra (dashed lines) of BSC and BSCF, respectively, depicting the addition of $\mathrm{Co}-\mathrm{O}$ neighbors during the anodic polarization. The additional $\mathrm{Co}-\mathrm{O}$ neighbors can be ascribed to the formation of the $\mathrm{Co}-\mathrm{O}(\mathrm{OH})$ layers formed at the surface which consist of a fully coordinated Co atoms (i.e. $6 \mathrm{O}$ neighbors). The difference spectra of BSC shows a smaller increase of the amplitude of the $\mathrm{Co}-\mathrm{O}$ peak than that of BSCF, which complies with the extents of shifts in their Co K-edge energy positions extracted from XANES spectra (see Figure $3 \mathrm{C}$ and d). In contrast, BSCF, in the presence of $\mathrm{Fe}$, reveals a greater change of the amplitude of $\mathrm{Co}-\mathrm{O}$ peak in its difference spectra, which again highlights the larger extent of increase in its Co oxidation state associated to the development of oxy(hydroxide) layer during the OER process.

More evident changes are revealed by the second peak of the difference spectra which describe changes of the CoCo coordination shells of BSC and BSCF from their state recorded at 1.2 $\mathrm{V}_{\mathrm{RHE}}$. As the comparison of Co K-edge FTEXAFS spectra showed more noticeable development of $\mathrm{Co}-\mathrm{O}(\mathrm{OH})$ layer for BSCF than BSC, the increase of amplitude of this particular $\mathrm{Co}-\mathrm{Co}$ peak is made clearer by plotting their difference spectra (dashed lines in Figure 4a and b). For a better reading of the peak amplitude changes during the anodic polarization, Figure $4 \mathrm{C}$ is constructed marking the corresponding peak height at $2.8 \AA$ of each difference spectra at each step of increasing potential. Interestingly, for both BSC and BSCF, similar tendencies of amplitude change of the $\mathrm{Co}-\mathrm{Co}$ peak associate with $\mathrm{Co}-\mathrm{O}(\mathrm{OH})$ are observed with the increase of Co oxidation states inferred from the positive edge shifts of Co K-edges (Figure 3d); the amplitude shows a rapid increase as the applied potential is increased over the OER onset potential $(\sim 1.4$ $\left.\mathrm{V}_{\mathrm{RHE}}\right)$. This tendency of increase in amplitude of the $\mathrm{Co}-\mathrm{Co}$ peak consolidates the previously assigned potential-induced construction of an active oxy(hydroxide) layer during the OER process. This further corroborates that the rapid increase of oxidation state beyond the OER onset regime is indeed consequential to the formation of oxy(hydroxide) layer, which in turn corresponds to high OER activity. Also, the difference spectra of BSCF reveal a higher increase of the Co-Co peak amplitude during the polarization than BSC indicating that relatively more $\mathrm{Co}(/ \mathrm{Fe})$ oxy(hydroxide) is formed. The corresponding peaks of difference spectra were fitted to corroborate the above findings (described in Supplementary Information S8).

Given that perovskite catalysts serves as substrate for the growth of the self-assembled $\mathrm{Co}-\mathrm{O}(\mathrm{OH})$ layer, the formation of oxy(hydroxide) layer is finite as observed during the in situ stability tests as summarized in Figure Size-h. Both BSC and BSCF revealed insignificant changes in their oxidation state, and their FT-EXAFS spectra after 100 cycles, which signifies a limited growth of a $\mathrm{Co}-\mathrm{O}(\mathrm{OH})$ layer (see Figure Size-h). Note, that the stability test was carried out subsequent to the series of chronoamperometry measurement during which the oxy(hydroxide) layer already have developed.

Lastly, note operando XAS measurements show that the Fe K-edge position in both LSCF and BSCF experience insignificant changes in its oxidation state during the anodic polarization (Figure S21a and b, respectively). The insignificant changes in the Fe K-edge position of XANES collected at each potential step indicate that the oxidation state of Fe is unchanged. This result agrees with previous studies in which co-presence of Fe aids to enhance catalytic activity of other transition metals (i.e. Ni) while Fe maintains its initial oxidation state. ${ }^{35}, 82-83$ Overall, our findings suggest that Fe would convey synergetic effects with Co to enhance its catalytic performance while not having to undergo substantial changes in its intrinsic properties.

\section{CONCLUSION}

In this study, a systematic assessment is made to understand the functional role of $\mathrm{Fe}$ in perovskite catalysts with respect to OER activity and stability by comparing the Fedoped Co-based perovskites - BSCF and LSCF - to the respective control samples without Fe - BSC and LSC. From this comparison, enhancements in both OER activity and stability are measured in the presence of Fe, despite that it constitutes only $\sim 5 \mathrm{wt} . \%$ of the perovskite oxide. In the light of our findings, such enhancement of overall electrochemical performance is suggested to be induced by the following effects that the Fe-doping brings upon a Cobased perovskite catalyst: i) charge stabilization of $\mathrm{Co}$ in a lower oxidation state, which also prevents possible formation of side oxide phase during synthesis by flame spray pyrolysis; ii) subsequently, the absence of side oxide phases enables maximization of the perovskite oxide surface to be available for the confined formation of a self-assembled oxy(hydroxide) layer; iii) Fe expands the potential range of thermodynamic meta-stability which improves stability of the perovskite oxide structure to serve as substrate for the growth of oxy(hydroxide) layer under the OER conditions. Interestingly, although the Fe-doping in Co-based perovskite catalysts conveys a positive influence on OER, the oxidation state of Fe in LSCF and BSCF does not undergo significant changes. In summary, these results show that $\mathrm{Fe}$ ultimately contributes to attain a higher OER activity and stability of perovskite catalysts. Overall, this study provides valuable insights into the specific role of Fe which 
guides directions for the future design of an ideal perovskite oxide for oxygen evolution reaction.

\section{ASSOCIATED CONTENT}

\section{Supporting Information.}

Physical characterizations (XRD and TEM); summary of electrochemical studies; theoretical B-site cation charges and Pourbaix diagrams of all materials based on density-functional theory computations; representation of edge-sharing and corner-sharing polyhedra in EXAFS spectra; operando EXAFS spectra fittings; verification of -oxy(hydroxide) development through difference spectra and multivariate curve resolution analysis; Fe K-edge XANES spectra of BSCF and LSCF.

\section{AUTHOR INFORMATION}

\section{Corresponding Author}

* E-mail: joseph.kim@psi.ch. Tel: +41 563104580.

* E-mail: emiliana.fabbri@psi.ch. Tel: +41 563102795.

\section{Author Contributions}

All authors have given approval to the final version of the manuscript.

\section{ACKNOWLEDGMENT}

The authors gratefully acknowledge the Swiss National Science Foundation through its Ambizione Program and the NCCR Marvel, the Swiss Competence Center for Energy Research (SCCER) Heat \& Electricity Storage through Innosuisse, Switzerland, and Paul Scherrer Institute for financial contributions to this work, respectively. The authors thank the Swiss Light Source for providing beamtime at the SuperXAS beamline.

\section{REFERENCES}

(1) Fabbri, E.; Nachtegaal, M.; Binninger, T.; Cheng, X.; Kim, B. J.; Durst, J.; Bozza, F.; Graule, T.; Schaublin, R.; Wiles, L.; Pertoso, M.; Danilovic, N.; Ayers, K. E.; Schmidt, T. J., Dynamic surface self-reconstruction is the key of highly active perovskite nanoelectrocatalysts for water splitting. Nat. Mater. 2017, 16 (9), 925.

(2) Cheng, X.; Fabbri, E.; Kim, B.; Nachtegaal, M.; Schmidt, T. J., Effect of ball milling on the electrocatalytic activity of Bao. 5 Sro.5Coo.8Feo.2 $\mathrm{O}_{3}$ towards the oxygen evolution reaction. I. Mater. Chem. A 2017, 5 (25), 13130-13137.

(3) Suntivich, J.; May, K. J.; Gasteiger, H. A.; Goodenough, J. B.; Shao-Horn, Y., A Perovskite Oxide Optimized for Oxygen Evolution Catalysis from Molecular Orbital Principles. Science 2011, 334 (6061), 1383-1385.

(4) Fabbri, E.; Nachtegaal, M.; Cheng, X.; Schmidt, T. J., Superior Bifunctional Electrocatalytic Activity of Bao.5Sro.5Coo.8Feo.2O3-/Carbon Composite Electrodes: Insight into the Local Electronic Structure. Adv. Energy Mater. 2015, 5 (17), 1402033.

(5) Fabbri, E.; Habereder, A.; Waltar, K.; Kotz, R.; Schmidt, T. J., Developments and perspectives of oxide-based catalysts for the oxygen evolution reaction. Catal. Sci. Technol. 2014, 4 (11), 38003821.

(6) Man, I. C.; Su, H. Y.; Calle-Vallejo, F.; Hansen, H. A.; Martinez, J. I.; Inoglu, N. G.; Kitchin, J.; Jaramillo, T. F.; Norskov, J. K.; Rossmeisl, J., Universality in Oxygen Evolution Electrocatalysis on Oxide Surfaces. ChemCatChem 2011, 3 (7), 1159-1165.

(7) Cheng, X.; Fabbri, E.; Nachtegaal, M.; Castelli, I. E.; El Kazzi, M.; Haumont, R.; Marzari, N.; Schmidt, T. J., Oxygen Evolution
Reaction on $\mathrm{La1}_{-\mathrm{xSrxCoO}}$ Perovskites: A Combined Experimental and Theoretical Study of Their Structural, Electronic, and Electrochemical Properties. Chem. Mater. 2015, 27 (22), $7662-7672$.

(8) Lim, T.; Niemantsverdriet, J. W.; Gracia, J., Layered Antiferromagnetic Ordering in the Most Active Perovskite Catalysts for the Oxygen Evolution Reaction. ChemCatChem 2016, 8 (18), 2968-2974.

(9) Calle-Vallejo, F.; Diaz-Morales, O. A.; Kolb, M. J.; Koper, M. T. M., Why Is Bulk Thermochemistry a Good Descriptor for the Electrocatalytic Activity of Transition Metal Oxides? ACS Catal. 2015, 5 (2), 869-873.

(10) Bockris, J. O.; Otagawa, T., The Electrocatalysis of Oxygen Evolution on Perovskites. I. Electrochem. Soc. 1984, 131 (2), 290302.

(11) Matsumoto, Y.; Yamada, S.; Nishida, T.; Sato, E., Oxygen Evolution on La1-xSrxEe1-yCoyO 3 Series Oxides. I. Electrochem. Soc. 1980, 127 (11), 2360-2364.

(12) Chang, S. H.; Danilovic, N.; Chang, K. C.; Subbaraman, R.; Paulikas, A. P.; Fong, D. D.; Highland, M. J.; Baldo, P. M.; Stamenkovic, V. R.; Freeland, J. W.; Eastman, J. A.; Markovic, N. M., Functional links between stability and reactivity of strontium ruthenate single crystals during oxygen evolution. Nat. Commun. 2014, 5, 4191.

(13) Cheng, X.; Fabbri, E.; Yamashita, Y.; Castelli, I. E.; Kim, B.; Uchida, M.; Haumont, R.; Puente-Orench, I.; Schmidt, T. J., Oxygen Evolution Reaction on Perovskites: A Multieffect Descriptor Study Combining Experimental and Theoretical Methods. ACS Catal. 2018, 9567-9578.

(14) Suntivich, J.; Gasteiger, H. A.; Yabuuchi, N.; Nakanishi, H.; Goodenough, J. B.; Shao-Horn, Y., Design principles for oxygenreduction activity on perovskite oxide catalysts for fuel cells and metal-air batteries. Nat. Chem. 2011, 3 (7), 546-550.

(15) Bockris, J. O.; Otagawa, T., The Electrocatalysis of Oxygen Evolution on Perovskites. IElectrochem Soc 1984, 131 (2), 290-302.

(16) Man, I. C.; Su, H. Y.; Calle-Vallejo, F.; Hansen, H. A.; Martinez, J. I.; Inoglu, N. G.; Kitchin, J.; Jaramillo, T. F.; Norskov, J. K.; Rossmeisl, J., Universality in Oxygen Evolution Electrocatalysis on Oxide Surfaces. Chemcatchem 2011, 3, 1159-1165.

(17) Suntivich, J.; May, K. J.; Gasteiger, H. A.; Goodenough, J. B.; Shao-Horn, Y., A Perovskite Oxide Optimized for Oxygen Evolution Catalysis from Molecular Orbital Principles. Science 2011, 334, 1383-1385.

(18) Matsumoto, Y.; Yamada, S.; Nishida, T.; Sato, E., Oxygen Evolution on La1-Xsrxfe1-Ycoyo3 Series Oxides. I Electrochem Soc 1980, 127, 2360-2364.

(19) Fabbri, E.; Schmidt, T. J., Oxygen Evolution Reaction-The Enigma in Water Electrolysis. ACS Catal. 2018, 8 (10), 9765-9774.

(20) Risch, M.; Khare, V.; Zaharieva, I.; Gerencser, L.; Chernev, P.; Dau, H., Cobalt-Oxo Core of a Water-Oxidizing Catalyst Film. I. Am. Chem. Soc. 2009, 131 (20), 6936.

(21) Risch, M.; Ringleb, F.; Kohlhoff, M.; Bogdanoff, P.; Chernev, P.; Zaharieva, I.; Dau, H., Water oxidation by amorphous cobaltbased oxides: in situ tracking of redox transitions and mode of catalysis. Energy Environ. Sci. 2015, 8 (2), 661-674.

(22) Klingan, K.; Ringleb, F.; Zaharieva, I.; Heidkamp, J.; Chernev, P.; Gonzalez-Flores, D.; Risch, M.; Fischer, A.; Dau, H., Water Oxidation by Amorphous Cobalt-Based Oxides: Volume Activity and Proton Transfer to Electrolyte Bases. Chemsuschem 2014, 7 (5), 1301-1310.

(23) Burke, M. S.; Zou, S. H.; Enman, L. J.; Kellon, J. E.; Gabor, C. A.; Pledger, E.; Boettcher, S. W., Revised Oxygen Evolution Reaction Activity Trends for First-Row Transition-Metal (Oxy)hydroxides in Alkaline Media. I. Phys. Chem. Lett. 2015, 6 (18), 3737-3742.

(24) Bergmann, A.; Martinez-Moreno, E.; Teschner, D.; Chernev, P.; Gliech, M.; de Araujo, J. F.; Reier, T.; Dau, H.; Strasser, 
P., Reversible amorphization and the catalytically active state of crystalline $\mathrm{Co}_{3} \mathrm{O}_{4}$ during oxygen evolution. Nat. Commun. 2015, 6,8625 .

(25) Kanan, M. W.; Nocera, D. G., In situ formation of an oxygen-evolving catalyst in neutral water containing phosphate and Co2+. Science 2008, 321 (5892), 1072-1075.

(26) Zhang, M.; de Respinis, M.; Frei, H., Time-resolved observations of water oxidation intermediates on a cobalt oxide nanoparticle catalyst. Nat. Chem. 2014, 6 (4), 362-367.

(27) Burke, M. S.; Enman, L. J.; Batchellor, A. S.; Zou, S. H.; Boettcher, S. W., Oxygen Evolution Reaction Electrocatalysis on Transition Metal Oxides and (Oxy)hydroxides: Activity Trends and Design Principles. Chem. Mater. 2015, 27 (22), 7549-7558.

(28) Mefford, J. T.; Rong, X.; Abakumov, A. M.; Hardin, W. G.; Dai, S.; Kolpak, A. M.; Johnston, K. P.; Stevenson, K. J., Water electrolysis on La1-xSrxCoO3-delta perovskite electrocatalysts. Nat. Commun. 2016, 7, 11053.

(29) Burke, M. S.; Kast, M. G.; Trotochaud, L.; Smith, A. M.; Boettcher, S. W., Cobalt-Iron (Oxy)hydroxide Oxygen Evolution Electrocatalysts: The Role of Structure and Composition on Activity, Stability, and Mechanism. I. Am. Chem. Soc. 2015, 137 (10), 3638-3648.

(30) Gong, M.; Li, Y. G.; Wang, H. L.; Liang, Y. Y.; Wu, J. Z.; Zhou, J. G.; Wang, J.; Regier, T.; Wei, F.; Dai, H. J., An Advanced Ni-Fe Layered Double Hydroxide Electrocatalyst for Water Oxidation. I. Am. Chem. Soc. 2013, 135 (23), 8452-8455.

(31) Zou, S. H.; Burke, M. S.; Kast, M. G.; Fan, J.; Danilovic, N.; Boettcher, S. W., Fe (Oxy)hydroxide Oxygen Evolution Reaction Electrocatalysis: Intrinsic Activity and the Roles of Electrical Conductivity, Substrate, and Dissolution. Chem. Mater. 2015, 27 (23), 8011-8020.

(32) Trotochaud, L.; Young, S. L.; Ranney, J. K.; Boettcher, S. W., Nickel-Iron Oxyhydroxide Oxygen-Evolution Electrocatalysts: The Role of Intentional and Incidental Iron Incorporation. I. Am. Chem. Soc. 2014, 136 (18), 6744-6753.

(33) Dionigi, F.; Strasser, P., NiFe-Based (Oxy)hydroxide Catalysts for Oxvgen Evolution Reaction in Non-Acidic Electrolytes. Adv. Energy Mater. 2016, 6 (23), 1600621.

(34) Chen, J. Y. C.; Dang, L. N.; Liang, H. F.; Bi, W. L.; Gerken, J. B.; Jin, S.; Alp, E. E.; Stahl, S. S., Operando Analysis of NiFe and Fe Oxyhydroxide Electrocatalysts for Water Oxidation: Detection of $\mathrm{Fe}_{4}+$ by Mossbauer Spectroscopy. I. Am. Chem. Soc. 2015, 137 (48), 15090-15093.

(35) Gorlin, M.; Chernev, P.; de Araujo, J. F.; Reier, T.; Dresp, S.; Paul, B.; Krahnert, R.; Dau, H.; Strasser, P., Oxygen Evolution Reaction Dynamics, Faradaic Charge Efficiency, and the Active Metal Redox States of Ni-Fe Oxide Water Splitting Electrocatalysts. I. Am. Chem. Soc. 2016, 138 (17), 5603-5614.

(36) Gorlin, M.; de Araujo, J. F.; Schmies, H.; Bernsmeier, D.; Dresp, S.; Gliech, M.; Jusys, Z.; Chernev, P.; Kraehnert, R.; Dau, H.; Strasser, P., Tracking Catalyst Redox States and Reaction Dynamics in Ni-Fe Oxyhydroxide Oxygen Evolution Reaction Electrocatalysts: The Role of Catalyst Support and Electrolyte $\mathrm{pH}$. I. Am. Chem. Soc. 2017, 139 (5), 2070-2082.

(37) Abbott, D. F.; Fabbri, E.; Borlaf, M.; Bozza, F.; Schäublin, R.; Nachtegaal, M.; Graule, T.; Schmidt, T. J., Operando X-ray absorption investigations into the role of $\mathrm{Fe}$ in the electrochemical stability and oxygen evolution activity of Ni1-xFexOy nanoparticles. J. Mater. Chem. A 2018.

(38) Kruidhof, H.; Bouwmeester, H. J. M.; Vondoorn, R. H. E.; Burggraaf, A. J., Influence of Order-Disorder Transitions on Oxygen Permeability through Selected Nonstoichiometric Perovskite-Type Oxides. Solid State Ionics 1993, 63-5, 816-822.

(39) Chen, Z. H.; Ran, R.; Zhou, W.; Shao, Z. P.; Liu, S. M., Assessment of Bao.5Sro.5Co1-yFeyO3-delta (y=0.0-1.0) for prospective application as cathode for IT-SOFCs or oxygen permeating membrane. Electrochim. Acta. 2007, 52 (25), 73437351.

(40) Han, B. H.; Grimaud, A.; Giordano, L.; Hong, W. T.; DiazMorales, O.; Yueh-Lin, L.; Hwang, J.; Charles, N.; Stoerzinger, K. A.; Yang, W. L.; Koper, M. T. M.; Shao-Horn, Y., Iron-Based Perovskites for Catalyzing Oxygen Evolution Reaction. I. Phys. Chem. C 2018, 122 (15), 8445-8454.

(41) Wang, Z.; Li, M.; Liang, C. H.; Fan, L. Q.; Han, J. N.; Xiong, Y. P., Effect of morphology on the oxygen evolution reaction for Lao.8Sro.2Coo.2Feo.8O3-delta electrochemical catalyst in alkaline media. RSC Adv. 2016, 6 (73), 69251-69256.

(42) Zhao, B. T.; Zhang, L.; Zhen, D. X.; Yoo, S.; Ding, Y.; Chen, D. C.; Chen, Y.; Zhang, Q. B.; Doyle, B.; Xiong, X. H.; Liu, M. L., A tailored double perovskite nanofiber catalyst enables ultrafast oxygen evolution. Nat. Commun. 2017, 8, 14586.

(43) Adolphsen, J. Q.; Sudireddy, B. R.; Gil, V.; Chatzichristodoulou, C., Oxygen Evolution Activity and Chemical Stability of $\mathrm{Ni}$ and Fe Based Perovskites in Alkaline Media. I. Electrochem. Soc. 2018, 165 (10), F827-F835.

(44) Landon, J.; Demeter, E.; Inoglu, N.; Keturakis, C.; Wachs, I. E.; Vasic, R.; Frenkel, A. I.; Kitchin, J. R., Spectroscopic Characterization of Mixed Fe-Ni Oxide Electrocatalysts for the Oxygen Evolution Reaction in Alkaline Electrolytes. ACS Catal. 2012, 2 (8), 1793-1801.

(45) Zhu, Y. L.; Zhou, W.; Chen, Z. G.; Chen, Y. B.; Su, C.; Tade, M. O.; Shao, Z. P., SrNbo.1Coo.7Feo.2O3-delta Perovskite as a Next-Generation Electrocatalyst for Oxygen Evolution in Alkaline Solution. Angew. Chem. Int. Edit. 2015, 54 (13), 3897-3901.

(46) Zhu, Y. L.; Zhou, W.; Chen, Y. B.; Yu, J.; Liu, M. L.; Shao, Z. P., A High-Performance Electrocatalyst for Oxygen Evolution Reaction: LiCoo.8Feo.2O2. Advanced Materials 2015, 27 (44), 7150.

(47) Heel, A.; Holtappels, P.; Hug, P.; Graule, T., Flame Spray Synthesis of Nanoscale Lao.65Sro.4Coo.2Feo.8O3-delta and Bao.5Sro.5Coo.8Feo.2O3-delta as Cathode Materials for Intermediate Temperature Solid Oxide Fuel Cells. Fuel Cells 2010, 10 (3), 419-432.

(48) Muller, O.; Nachtegaal, M.; Just, J.; Lutzenkirchen-Hecht, D.; Frahm, R., Quick-EXAFS setup at the SuperXAS beamline for in situ X-ray absorption spectroscopy with $10 \mathrm{~ms}$ time resolution. I. Synchrotron Radiat. 2016, 23, 260-266.

(49) Ravel, B.; Newville, M., ATHENA, ARTEMIS, HEPHAESTUS: data analysis for X-ray absorption spectroscopy using IFEFFIT. I. Synchrotron Radiat. 2005, 12, 537-541.

(50) Delaplane, R. G.; Ibers, J. A.; Ferraro, J. R.; Rush, J. J., Diffraction and Spectroscopic Studies of Cobaltic Acid System Hcoo2-Dcoo2. I. Chem. Phys. 1969, 50 (5), 1920-1927.

(51) Pertlik, F., The distortion of the hexagonal close packing of oxygen atoms in $\mathrm{Co}(\mathrm{OH})(2)$ compared to isotypic brucite-type structures. Monatsh. Chem. 1999, 130 (9), 1083-1088.

(52) Wold, A.; Ward, R., Perowskite-Type Oxides of Cobalt, Chromium and Vanadium with Some Rare Earth Elements. $\underline{\text { I. Am. }}$ Chem. Soc. 1954, 76 (4), 1029-1030.

(53) Schmidt, T. J.; Gasteiger, H. A.; Stab, G. D.; Urban, P. M.; Kolb, D. M.; Behm, R. J., Characterization of high-surface area electrocatalysts using a rotating disk electrode configuration. I. Electrochem. Soc. 1998, 145 (7), 2354-2358.

(54) Suntivich, J.; Gasteiger, H. A.; Yabuuchi, N.; Shao-Horn, Y., Electrocatalytic Measurement Methodology of Oxide Catalysts Using a Thin-Film Rotating Disk Electrode. I. Electrochem. Soc. 2010, 157 (8), B1263-B1268.

(55) Binninger, T.; Fabbri, E.; Patru, A.; Garganourakis, M.; Han, J.; Abbott, D. F.; Sereda, O.; Kotz, R.; Menzel, A.; Nachtegaal, M.; Schmidt, T. J., Electrochemical Flow-Cell Setup for In Situ X-ray Investigations I. Cell for SAXS and XAS at Synchrotron Facilities. L. Electrochem. Soc. 2016, 163 (10), H9o6-H912.

(56) Castelli, I. E.; Huser, F.; Pandey, M.; Li, H.; Thygesen, K. S.; Seger, B.; Jain, A.; Persson, K. A.; Ceder, G.; Jacobsen, K. W., New 
Light-Harvesting Materials Using Accurate and Efficient Bandgap Calculations. Adv. Energy Mater. 2015, 5 (2), 1400915.

(57) The Materials Project. https://materialsproject.org/ (accessed Nov. 2017).

(58) Johnson, J. W.; Oelkers, E. H.; Helgeson, H. C., Supcrt92 a Software Package for Calculating the Standard Molal Thermodynamic Properties of Minerals, Gases, Aqueous Species, and Reactions from 1-Bar to 5000-Bar and o-Degrees- $C$ to $1000-$ Degrees-C. Comput. Geosci. 1992, 18 (7), 899-947.

(59) Pourbaix, M., Atlas of electrochemical equilibria in aqueous solutions. Pergamon Press: 1966.

(6o) Larsen, A. H.; Mortensen, J. J.; Blomqvist, J.; Castelli, I. E.; Christensen, R.; Dulak, M.; Friis, J.; Groves, M. N.; Hammer, B.; Hargus, C.; Hermes, E. D.; Jennings, P. C.; Jensen, P. B.; Kermode, J.; Kitchin, J. R.; Kolsbjerg, E. L.; Kubal, J.; Kaasbjerg, K.; Lysgaard, S.; Maronsson, J. B.; Maxson, T.; Olsen, T.; Pastewka, L.; Peterson, A.; Rostgaard, C.; Schiotz, J.; Schutt, O.; Strange, M.; Thygesen, K. S.; Vegge, T.; Vilhelmsen, L.; Walter, M.; Zeng, Z. H.; Jacobsen, K. W., The atomic simulation environment-a Python library for working with atoms. I. Phys.: Condens. Mat. 2017, 29 (27), 273002.

(61) Persson, K. A.; Waldwick, B.; Lazic, P.; Ceder, G., Prediction of solid-aqueous equilibria: Scheme to combine first-principles calculations of solids with experimental aqueous states. Phys. Rev. B 2012, 85 (23).

(62) Castelli, I. E.; Thygesen, K. S.; Jacobsen, K. W., Calculated optical absorption of different perovskite phases. I. Mater. Chem. A 2015, 3 (23), 12343-12349.

(63) Giannozzi, P.; Baroni, S.; Bonini, N.; Calandra, M.; Car, R.; Cavazzoni, C.; Ceresoli, D.; Chiarotti, G. L.; Cococcioni, M.; Dabo, I.; Dal Corso, A.; de Gironcoli, S.; Fabris, S.; Fratesi, G.; Gebauer, R.; Gerstmann, U.; Gougoussis, C.; Kokalj, A.; Lazzeri, M.; MartinSamos, L.; Marzari, N.; Mauri, F.; Mazzarello, R.; Paolini, S.; Pasquarello, A.; Paulatto, L.; Sbraccia, C.; Scandolo, S.; Sclauzero, G.; Seitsonen, A. P.; Smogunov, A.; Umari, P.; Wentzcovitch, R. M., QUANTUM ESPRESSO: a modular and open-source software project for quantum simulations of materials. I. Phys.: Condens. Mat. 2009, 21 (39), 395502.

(64) Perdew, J. P.; Ruzsinszky, A.; Csonka, G. I.; Vydrov, O. A.; Scuseria, G. E.; Constantin, L. A.; Zhou, X. L.; Burke, K., Restoring the density-gradient expansion for exchange in solids and surfaces. Phys. Rev. Lett. 2008, 100 (13).

(65) Standard Solid State Pseudopotential Library. http://materialscloud.org/sssp.

(66) Prandini, G.; Marrazzo, A.; Castelli, I. E.; Mounet, N.; Marzari, N. Precision and efficiency in solid-state pseudopotential calculations; Cornell University: June 14, 2018, 2018; p https://arxiv.org/abs/1806.05609.

(67) Mortensen, J. J.; Hansen, L. B.; Jacobsen, K. W., Real-space grid implementation of the projector augmented wave method. Phys. Rev. B 2005, 71 (3), 035109.

(68) Enkovaara, J.; Rostgaard, C.; Mortensen, J. J.; Chen, J.; Dulak, M.; Ferrighi, L.; Gavnholt, J.; Glinsvad, C.; Haikola, V.; Hansen, H. A.; Kristoffersen, H. H.; Kuisma, M.; Larsen, A. H.; Lehtovaara, L.; Ljungberg, M.; Lopez-Acevedo, O.; Moses, P. G.; Ojanen, J.; Olsen, T.; Petzold, V.; Romero, N. A.; StausholmMoller, J.; Strange, M.; Tritsaris, G. A.; Vanin, M.; Walter, M.; Hammer, B.; Hakkinen, H.; Madsen, G. K. H.; Nieminen, R. M.; Norskov, J.; Puska, M.; Rantala, T. T.; Schiotz, J.; Thygesen, K. S.; Jacobsen, K. W., Electronic structure calculations with GPAW: a real-space implementation of the projector augmented-wave method. I. Phys.: Condens. Mat. 2010, 22 (25), 253202.

(69) Bader, R. F. W., Atoms in Molecules: A Quantum Theory. Clarendon Press: 1994. (7o) Raebiger, H.; Lany, S.; Zunger, A., Charge self-regulation upon changing the oxidation state of transition metals in insulators. Nature 2008, 453 (7196), 763-766.

(71) Kim, B.-J.; Cheng, X.; Abbott, D. F.; Fabbri, E.; Bozza, F.; Graule, T.; Castelli, I. E.; Wiles, L.; Danilovic, N.; Ayers, K. E.; Marzari, N.; Schmidt, T. J., Highly Active Nanoperovskite Catalysts for Oxygen Evolution Reaction: Insights into Activity and Stability of Bao.5Sro. ${ }_{5} \mathrm{Coo}_{2} 8 \mathrm{Feo}_{2} \mathrm{O}_{2}+\delta$ and $\mathrm{PrBaCo}_{2} \mathrm{O}_{5}+\delta$. Adv. Funct. Mater., 1804355.

(72) Bajdich, M.; Garcia-Mota, M.; Vojvodic, A.; Norskov, J. K.; Bell, A. T., Theoretical Investigation of the Activity of Cobalt Oxides for the Electrochemical Oxidation of Water. I. Am. Chem. Soc. 2013, 135 (36), 13521-13530.

(73) Battle, P. D.; Gibb, T. C.; Strange, R., A Study of a New Incommensurate Phase in the System Srmn1-Xсоxо3-Y. I. Solid. State. Chem. 1989, 81 (2), 217-229.

(74) Gibb, T. C., Evidence for an Unusual Phase in the Perovskite-Related System Bacoxmn1-Xo3-Y from Exafs Spectroscopy. I. Mater. Chem. 1992, 2 (4), 387-393.

(75) Huang, J. H.; Liu, Q. H.; Yao, T.; Pan, Z. Y.; Wei, S. Q., XAFS study on structure-activity correlations of alpha-Co(OH)(2) nanosheets water oxidation catalysts. J. Phys. Conf. Ser. 2016, 712, 012128.

(76) Huang, J. H.; Shang, Q. C.; Huang, Y. Y.; Tang, F. M.; Zhang, Q.; Liu, Q. H.; Jiang, S.; Hu, F. C.; Liu, W.; Luo, Y.; Yao, T.; Jiang, Y.; Pan, Z. Y.; Sun, Z. H.; Wei, S. Q., Oxyhydroxide Nanosheets with Highly Efficient Electron-Hole Pair Separation for Hydrogen Evolution. Angew. Chem. Int. Edit. 2016, 55 (6), 2137-2141.

(77) Totir, D.; Mo, Y. B.; Kim, S.; Antonio, M. R.; Scherson, D. A., In situ CoK-edge X-ray absorption fine structure of cobalt hydroxide film electrodes in alkaline solutions. I. Electrochem. Soc. 2000, 147 (12), 4594-4597.

(78) Yoo, J. S.; Rong, X.; Liu, Y. S.; Kolpak, A. M., Role of Lattice Oxygen Participation in Understanding Trends in the Oxygen Evolution Reaction on Perovskites. ACS Catal. 2018, 8 (5), 46284636.

(79) Grimaud, A.; Diaz-Morales, O.; Han, B. H.; Hong, W. T.; Lee, Y. L.; Giordano, L.; Stoerzinger, K. A.; Koper, M. T. M.; ShaoHorn, Y., Activating lattice oxygen redox reactions in metal oxides to catalyse oxygen evolution. Nat. Chem. 2017, 9 (5), 457-465.

(8o) Han, B. H.; Stoerzinger, K. A.; Tileli, V.; Gamalski, A. D.; Stach, E. A.; Shao-Horn, Y., Nanoscale structural oscillations in perovskite oxides induced by oxygen evolution. Nat. Mater. 2017, 16 (1), 121-126.

(81) Rong, X.; Parolin, J.; Kolpak, A. M., A Fundamental Relationship between Reaction Mechanism and Stability in Metal Oxide Catalysts for Oxygen Evolution. ACS Catal. 2016, 6 (2), 11531158.

(82) Friebel, D.; Louie, M. W.; Bajdich, M.; Sanwald, K. E.; Cai, Y.; Wise, A. M.; Cheng, M. J.; Sokaras, D.; Weng, T. C.; AlonsoMori, R.; Davis, R. C.; Bargar, J. R.; Norskov, J. K.; Nilsson, A.; Bell, A. T., Identification of Highly Active Fe Sites in (Ni,Fe)OOH for Electrocatalytic Water Splitting. I. Am. Chem. Soc. 2015, 137 (3), 1305-1313.

(83) Kotomin, E. A.; Mastrikov, Y. A.; Kuklja, M. M.; Merkle, R.; Roytburd, A.; Maier, J., First principles calculations of oxygen vacancy formation and migration in mixed conducting Bao.5Sro.5Co1-yFeyO3-delta perovskites. Solid State Ionics 2011, $188(1), 1-5$. 


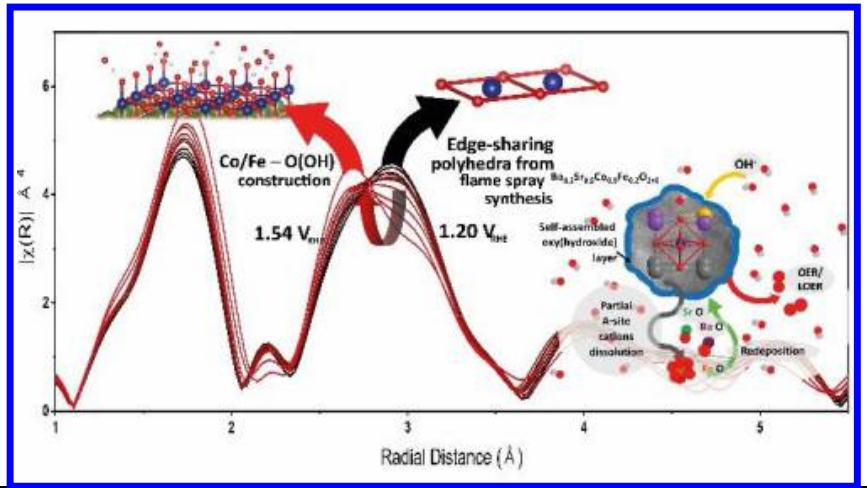

